\title{
Insubmissão voluntária: Tirania, servidão e liberdade em La Boétie
}

\author{
Voluntary Insubmission: \\ Tyranny, servitude, and freedom in La Boétie
}

Marcio Ferreira Rodrigues Pereira

Orcid: https://orcid.org/0000-0002-4949-1301 - E-mail: marciofrpereira@gmail.com

\begin{abstract}
RESUMO
Em tempos de escalada autoritária ao redor do globo, em que as estruturas autocráticas que nos circundam parecem, por vezes, demasiado colossais, pode ser proveitoso mobilizar autores capazes de oferecer não apenas modos enfrentamento à tirania, mas modos que estejam ao alcance do indivíduo. O "Discurso da servidão voluntária", de Étienne de La Boétie, segundo penso, insere-se dentro dessa perspectiva. Dentre outras coisas, fornece ferramentas potentes para o enfretamento da tirania tendo como ponto de partida os tiranizados, os próprios indivíduos. Nesse sentido, através do exame das noções de tirania, servidão e liberdade, o presente artigo deseja explorar essa chave de leitura da obra de La Boétie.
\end{abstract}

Palavras-chave: Tirania. Servidão. Liberdade. La Boétie.

\begin{abstract}
In times of authoritarian escalation around the globe, in which the autocratic structures that surround us sometimes seem too colossal, it can be beneficial to mobilize authors capable of offering not only ways of coping with tyranny, but ways that are within the reach of the individual. Étienne de La Boétie's "Discourse on Voluntary Servitude", I believe, falls within this perspective. Among other things, it provides powerful tools to face tyranny, taking as a starting
\end{abstract}


point the tyrannized ones, the individuals themselves. In this sense, by examining the notions of tyranny, servitude and freedom, the present article wishes to explore this interpretation of La Boétie's work.

Keywords: Tyranny. Servitude. Freedom. La Boétie.

\section{Introdução}

Gostaria de iniciar esse texto convidando o leitor a realizar um exercício: antes de prosseguir com a leitura do próximo parágrafo, peço que construa, mentalmente ou por escrito, como preferir, um rol contendo algumas questões que considere alarmantes do atual estado de coisas do mundo.

Fosse a mim acessível a lista de urgências elaborada pelo leitor, confesso que não me surpreenderia se esse rol, além de elaborado com certa agilidade, contivesse questões similares ou mesmo idênticas às minhas, tais como: mudança climática, escalada autoritária ao redor do globo, aprofundamento das desigualdades sociais, precarização do trabalho, persistência ou aumento do racismo e da xenofobia, dentre outras. Digo isso, em primeiro lugar, por experiência. Realizado esse mesmo exercício em sala de aula com meus alunos, além de a elaboração do rol de tópicos alarmantes por parte dos estudantes ter sido rápida, as questões indicadas foram muito próximas às minhas. Mas, para além disso, na verdade, não espanta que uma lista assim seja produzida de maneira veloz e que contenha questões similares às minhas pelo fato de que, hoje, temas como os enunciados acima (escalada autoritária ao redor do planeta, mudança climática, etc.) nos atravessam de forma tão premente e generalizada que torna compreensível (e até previsível) a produção de listas similares. Dito de outra forma, dada a nossa atual realidade socioeconômica - de intensa circulação de pessoas, mercadorias e informações - a interrelacionalidade dos problemas humanos parece que nunca esteve tão em evidência; o que pode explicar, portanto, a elaboração de listas parecidas. O que intriga, desse modo, não é o fato de uma lista assim ser produzida de forma ágil ou mesmo com conteúdo parecido, mas sim aquilo que pode ser resumido na seguinte indagação: por que nos é relativamente fácil chegar a um acordo sobre uma espécie de cahiers de doléances a respeito da ordem contemporânea e, ao mesmo tempo, tão difícil desobedecer à essa mesma ordem? Afinal, por que obedecemos? Por que, muitas vezes, nos comportamos como espectadores de um desastre?

Em geral, foi o tema da desobediência (e não o da obediência) que fascinou/fascina muitos autores'. "Quais fatores desencadearam a Revolução Francesa?", "o Maio de 68?", "a Primavera Árabe?", "as Jornadas de Junho?". Nesse sentido, a pergunta fundamental do filósofo, do cientista político, do jurista, costuma ser: por que as pessoas se revoltam? Nesse texto, porém, nosso enfoque será outro. Queremos entender não por que as pessoas se insurgem, mas, ao contrário, por que não o fazem, o tempo todo. Dito de outra forma, desejamos refletir sobre o que leva as pessoas a aderirem a estruturas que as oprimem, ou ainda, o que leva multidões inteiras a trabalharem pela sua servidão. ${ }^{2}$

Dentre outros, um autor que nos auxilia nessa investigação é Étienne de La Boétie. Mais especificamente, as leituras que o autor oferece sobre os temas da tirania, servidão e liberdade

\footnotetext{
1 Para ficar apenas com um exemplo da filosofia moderna, um dos mais notórios (diga-se de passagem), pode-se argumentar que uma das preocupações centrais de Hobbes em "O Leviatã" é a desobediência. A preocupação do autor em erguer um governo central forte trata-se, dentre outras coisas, de um mecanismo para se evitar a desobediência. (HOBBES, 1983).

2 Na leitura que Deleuze e Guattari (2010, p. 46) conferem a Espinosa, a questão pode ser colocada da seguinte forma: por que os homens lutam por sua servidão como se se tratasse da sua salvação?
} 
em seu "Discurso da servidão voluntária" se apresentam como perspectivas potentes para refletir sobre o tema da obediência e, de modo mais geral, sobre o próprio atual estado de coisas do mundo.

\section{Enigma da servidão voluntária}

Um estranho panfleto. Não apenas pelas controvérsias relacionadas à sua autoria ou pelos diferentes usos políticos que dele $\mathrm{se} \mathrm{fez}^{3}$, mas, antes, pelo seu próprio título, um oximoro ("Discurso da servidão voluntária") ${ }^{4}$. Lemos esse título e nos perguntamos: o que significa essa junção de palavras "servidão" (condição de escravo) "voluntária" (pela própria vontade)? Escravo pela própria vontade? Estamos diante de uma servidão desejada? Sim, a leitura da obra confirma a hipótese; o panfleto, de fato, faz uma análise da submissão não por coação, mas por desejo.

Porém, antes de aprofundarmos esse ponto, vale notar que já aqui, no título da obra, é possível colher uma primeira novidade do pensamento de La Boétie. Ao invés de o autor investigar a desobediência (como muitos antes e depois dele fizeram), sua análise, pelo contrário, recai sobre o tema da obediência. Mais especificamente, enquanto muitos autores examinaram a tirania do ponto de vista do tirano, elaborando, muitas vezes, "longas litanias moralizadoras sobre a profundidade do mal", La Boétie investigou aquela olhando para os tiranizados (GROS, 2018 , p. 51). O autor, nesse sentido, não quer explicar o tirano a partir de um ato violento, nem tampouco pela ideologia, mas com os olhos voltados para os tiranizados.

E é aplicando esse método de análise que La Boétie indaga aos tiranizados por que eles aceitam o tirano. "Como pode ser que tantos homens, tantos burgos, tantas cidades, tantas nações suportem às vezes um tirano só [?]" (LA BOÉTIE, 1999, p. 50). A resposta mais usual à pergunta é aquela que afirma que os tiranos têm as fortalezas, as armas, as leis, ou, para ficarmos com uma linguagem mais contemporânea, o monopólio da violência. Em suma, é, a princípio, por medo que os tiranizados se submetem ao tirano. Entretanto, La Boétie insiste e lembra aos tiranizados que o tirano é apenas um, um homem como outro qualquer, sendo, muitas vezes, inclusive o mais covarde de todos.

Mas, oh, bom Deus! O que pode ser isso? Como o denominaremos? Que desgraça é essa? Ou que vício? Ou, antes, que vício infeliz? Ver um número infinito de homens (...) sofrer as pilhagens, a libertinagem, as crueldades, não de um exército, não de um campo de bárbaros contra o qual tinham de derramar o sangue e a vida futura, mas de um só; não de um Hércules, nem de um Sansão, mas de um homúnculo e, muitas vezes, o mais covarde. (LA BOÉTIE, 1999, p. 33).

A questão que imediatamente se segue é: mas de onde vem então o corpo fantástico do tirano? Como é possível que apenas um homem - que só tem dois olhos, dois pés e dois braços - detenha fortalezas, armas, leis e que seja assim capaz de subjugar populações inteiras? Ao que o próprio La Boétie responde: são os próprios tiranizados que, em última análise, outorgam tal poder fantástico ao tirano. Em suas palavras:

\footnotetext{
3 Para uma visão mais detalhada a respeito das controvérsias e do contexto histórico do "Discurso da servidão voluntária" de La Boétie, consultar Chaui (1999, pp. 175-180), Gros (2018, pp. 48-49) e Kurz (1950). O panfleto é contemporâneo às rebeliões de Guyenne de 1548 (rebeliões camponesas decorrentes do imposto sobre o sal e que terminaram sendo reprimidas a sangue pelas tropas do rei Henrique II).

4 O panfleto também é conhecido como "Contra um" ("Contre'Un").
} 
Aquele que vos domina tanto só tem dois olhos, só tem duas mãos, só tem um corpo, e não tem outra coisa que o que tem o menor homem do grande e infinito número de vossas cidades, senão a vantagem que lhe dais para destruir-vos. De onde tirou tantos olhos com os quais vos espia, se não os colocais a serviço dele? Como tem tantas mãos para golpearvos, se não as toma de vós? Os pés com que espezinha vossas cidades, de onde lhe vêm senão dos vossos?" (LA BOÉTIE, 1999, p. 16).

E aqui, antes de prosseguirmos, é importante reforçar uma questão, embora ela já tenha sido sinalizada anteriormente. O tema do "Discurso sobre a servidão voluntária" não é, note-se bem, a mera obediência (todo o complexo de subordinações em relação ao qual estamos sempre em processo de negociação na vida social), nem tampouco a obediência por coação (num exemplo drástico, aquele que obedece para resguardar a própria vida ou a dos seus). 0 tema do autor, na verdade, é (como o título da obra deixa entrever) a obediência desejada, ativa, fervorosa. Para La Boétie, é esta que, no fim das contas, verdadeiramente sustenta e nutre a tirania. O que mantém governos tirânicos é a passagem da obediência à servidão (os aduladores, os delatores, os funcionários "zelosos", os carreiristas, etc.), ou ainda, na expressão de Gros (2018, p. 59), a passagem da obediência à superobediência.

Servir é mais que obedecer, é fornecer garantias, antecipar os desejos, obedecer o melhor possível, fazer de sua obediência a expressão de uma gratidão, justificar as ordens que nos dão; o que poderíamos chamar de "superobediência" (GROS, 2018, p. 59).

Mas é preciso ir além na investigação e indagar por que muitos tiranizados passam da obediência à servidão. Por que terminam por colocar seus olhos, braços e pés a serviço do tirano? Para La Boétie, muitos tiranizados assim o fazem por quererem o seu próprio quinhão de tirania. Como consequência, eles próprios se transformam em tiranetes, sujeitando todos aqueles que "abaixo" dele estão.

Contentam-se em suportar o mal para fazê-lo, não àquele que lhes malfaz, mas aos que, como eles, o suportam e nada podem fazer. (...) em verdade, o que é aproximar-se do tirano senão distanciar-se da liberdade e, por assim dizer, abraçar e apertar com as duas mãos a servidão? (LA BOÉTIE, 1999, pp. 100-101).

Assim, a relação de superobediência, longe de formar dois grupos separados e estáticos (tiranos e tiranizados) se espraia por todo o tecido social, gerando uma espécie de cumplicidade entre todos (GROS, 2018, p. 53). Como numa sala de espelhos ${ }^{5}$, em que a sociedade espelha o tirano e vice-versa, a tirania é, em última análise, um sistema que funciona em esquema de retroalimentação. "Cada qual leva sua parcela de prazer ao ser autorizado a ser o tirano de outrem" (GROS, 2018, p. 53). Desempenhando o duplo papel de tirano e tiranizado, formamos ao final uma multidão de tiranetes. O sistema de tirania encontra seu motor.

\section{Insubmissão voluntária (ou por uma obediência precária)}

A novidade do pensamento de La Boétie não está apenas em explicar a tirania a partir dos tiranizados. É possível colher outra inovação quando se examina a forma como o autor propõe enfrentá-la. Lançado o argumento de que é a passagem da obediência à servidão que, no fim das contas, mantém a tirania, era de se esperar que o autor esboçasse algum argumento no sentido de uma sublevação contra o tirano, de um assalto ao poder. Nada disso. La Boétie não nos con-

\footnotetext{
${ }^{5}$ Devo a imagem da sala de espelhos ao pesquisador Bruno Cava.
} 
voca à nenhuma insurreição. Sequer a desobediência é sugerida. Para o autor, o enfrentamento à tirania começa, antes de tudo, em nada lhe oferecer, isto é, em parar de superobedecer.

Não se deve tirar coisa alguma, e sim nada lhe dar (...). Não pretendo que o empurreis ou sacudais, somente não mais o sustentai, e o vereis como um grande colosso, de quem subtraiu-se a base, desmanchar-se com seu próprio peso e rebentar-se. (LA BOÉTIE, 1999, p. 77 e 16).

Se o que verdadeiramente dá sustentação à tirania (a superobediência) não é produto de uma coação exterior, então "a verdadeira revolução deve começar por uma abdicação interior" (GROS, 2018, p. 54). Deve-se, antes de tudo, "resistir não ao poder em suas formas instituídas", mas ao nosso desejo de servidão, "à nossa adoração pelo chefe", uma vez que são precisamente esse desejo e essa adoração que nutrem o tirano (GROS, 2018, p. 54). Nunca antecipar o desejo do um, abolir em nós qualquer princípio de adesão às estruturas tirânicas; pode-se dizer que é isso que La Boétie nos pedes para secar a árvore da tirania.

Como o fogo de uma fagulha torna-se grande e sempre aumenta, e quanto mais lenha encontra mais a devora, mas se consuma e acaba, apagando-se por si mesma quando param de alimentá-lo - assim também, por certo, os tiranos, quanto mais pilham, mais exigem; quanto mais arruinam e destroem, mais se lhes oferece, mais o empanturram; eles se fortalecem na mesma medida e estão cada vez mais dispostos a tudo aniquilar e destruir; mas se nada se lhes dá, se não se lhes obedece, sem combatê-los, sem atacá-los, ficam nus e desfeitos - semelhantes à árvore que, não recebendo mais sumo e alimento para sua raiz, em breve é apenas um galho seco e morto." (LA BOÉTIE, 1999, pp. 77-78).

Não se trata, portanto, nem mesmo de desobedecer, mas, como diz Gros (2018, p. 5657), de obedecer ao mínimo, buscando tornar a execução da tarefa cada vez pior, no limite de uma sabotagem. "Entre a colaboração franca e a resistência armada", La Boétie nos apresenta uma terceira via, a da submissão precária, arisca e permanentemente vigilante (GROS, 2018, p. 58-59). ${ }^{6}$

Por paradoxal que possa ser, a tirania depende de uma adesão nossa - leia-se: de nossa liberdade - por isso instável e frágil. Mas qual seria a noção de liberdade para La Boétie? Em uma passagem enigmática, que mais parece uma afronta não apenas aos nossos ouvidos, mas a todos aqueles que, de fato, sofrem as tiranias do poder, o autor diz: "para ter liberdade basta desejá-la, (...) basta um simples querer" (LA BOÉTIE, 1999, p. 15). E, em outra passagem, reafirma: "Só a liberdade os homens não desejam; ao que parece não há outra razão senão que, se a desejassem, tê-la-iam; como se se recusassem a fazer essa; bela aquisição só porque ela é demasiado fácil" (LA BOÉTIE, 1999, p. 15). Aqui, como adverte Gros (2018, p. 55), estamos longe de uma liberdade atravessada por determinações sociais ou jurídicas - a liberdade como condição material ou a liberdade como direito. Em La Boétie, a liberdade "é, antes de mais nada, uma disposição ética" (GROS, 2018, p. 55) E eu acrescentaria uma liberdade à la Bartleby: "I would prefer not to" ["Eu preferiria não fazer"] (MELVILLE, 2015). Liberdade, nesse sentido, é a possibilidade que temos de maquinar um outro desejo, de desejar diferente. Como diz Newman (2015, p. 63), "A liberdade, então, é simplesmente nossa servidão voluntária invertida, nossa inservidão [insubmissão] voluntária". Por isso que La Boétie diz: basta desejar a liberdade para obtê-la. "Ser livre é essencialmente querer ser livre" (GROS, 2018, p. 55). O panfleto, segundo pensamos, é assim mais do que uma explicação sobre a tirania, um chamado à liberdade.

\footnotetext{
6 O protagonista Bartleby, da obra homônima de Melville, ilustra bem a noção de submissão precária (MELVILLE, 2015).
} 


\section{Escala humana}

Das questões instigantes do pensamento de La Boétie, gostaria de destacar duas finais. A primeira, já deixei entrever ao longo do texto, mas, dado o seu caráter desconcertante, gostaria de retomá-la aqui. Quando pensamos em estruturas tirânicas, costumamos dar especial destaque a aspectos como o medo, a coação e a verticalidade prevalecendo nas relações sociais. Tais aspectos estão, de fato, presentes na tirania, sendo certo que, sob um governo tirânico, uma parcela considerável de pessoas agoniza com intimidações de todo tipo e sentem, muitas vezes, medo. Mas La Boétie nos recorda que isso é parte da história e não toda ela. A questão é que o realce que costumamos dar a esses aspectos das relações tirânicas (medo, coação e verticalidade) parece encobrir que também há, da parte de muitos, adesão, gozo e prazer. Aliás, conforme destacamos ao longo do texto, a tirania repousa precisamente no investimento desejante que nela fazemos. Assim, La Boétie nos lembra que é falsa a imagem de um tirano que governa e decide sozinho, isolado. Como diz Gros (2018, p. 53), "a representação vertical mascara a cadeia horizontal das cumplicidades e a parcela de compaixão prazerosa que cada um se vê oferecer em um regime tirânico". Por um lado, reconhecer e combater sempre a coação, o medo e a verticalidade da tirania; mas, por outro, nunca esquecer que o que verdadeiramente sustenta o sistema tirânico é o prazer. Eis a primeira novidade desconcertante de La Boétie.

Além disso, e de certa forma em articulação com a questão anterior, autores como La Boétie nos recordam de uma "escala humana" no fazer-política. Diante dos temas alarmantes que nos circundam (basta lembrar aqui do rol de questões que apontamos na introdução deste trabalho: mudança climática, escalada autoritária, etc.), não é incomum sentirmo-nos impotente. Os problemas, além de numerosos e complexos, são de uma escala de gigantes; isto é, projetam-se para muito além de um plano local, visível e bem demarcado. E é em meio a esse cenário agigantado, em meio a paisagens por vezes desoladoras, que a "escala humana" de La Boétie é precisamente valiosa. Ela não apenas nos recorda da responsabilidade que cada um, individualmente, pode estar tendo na manutenção de redes tirânicas. Mais que isso, ela nos lembra de ações que estão ao nosso alcance (ao alcance individual) - não superobedecer, maquinar um outro desejo, desejar diferente - e que tais ações não são pouca coisa. Cada um de nós conta.

\section{Referências bibliográficas}

CHAUI, M. Amizade, Recusa do Servir. Em: LA BOÉTIE, E. Discurso da servidão voluntária. São Paulo: Brasiliense, 1999.

DELEUZE, G.; GUATTARI, F. O Anti-Édipo. Capitalismo e esquizofrenia. São Paulo, Ed. 34, 2010.

GROS, F. Desobedecer. São Paulo: Ubu, 2018.

HOBBES, T. Leviatã ou matéria, forma e poder de um Estado eclesiástico e civil. $3^{\text {a }}$ ed. São Paulo: Abril Cultural, 1983.

KURZ, H. Montaigne and La Boétie in the Chapter on Friendship. Modern Language Association, Nova York, volume 65, número 4, 1950, pp. 483-530.

LA BOÉTIE, E. Discurso da servidão voluntária. São Paulo: Brasiliense, 1999.

MELVILLE, H. Bartleby, o escrevente. Uma história de Wall Street. São Paulo: Autêntica, 2015. 
NEWMAN, S. 'Critique Will Be the Art of Voluntary Inservitude'. Foucault, La Boétie and the Problem of Freedom. FUGGLE, S. et al. Foucault and the History of Our Present. Londres: Palgrave Macmillam, 2015.

\section{Sobre o autor}

Marcio Ferreira Rodrigues Pereira

Doutor em Filosofia pela Universidade de São Paulo e em Direito pela Queen's University (doutorado em cotutela). Professor da Universidade Federal do Ceará. Área de atuação: Filosofia Política.

Recebido em: 30/05/2020

Aprovado em: 24/07/2020 